\title{
UN BUEN PASTOR Y UNA DIVINA PASTORA ATRIBUIDOS AL CÍRCULO DEL PINTOR JUAN RUIZ SORIANO
}

\author{
A GOOD SHEPHERD AND A DIVINE SHEPHERDESS \\ ATTRIBUTED TO THE CIRCLE OF THE PAINTER \\ JUAN RUIZ SORIANO
}

\author{
Carmen de Tena Ramírez \\ Grupo de investigación HUM-213: Centro Investigación Patrimonio Artístico Andaluz \\ cdetena@us.es
}

\begin{abstract}
En este artículo presentamos una pareja de pinturas atribuidas al círculo del artista Juan Ruiz Soriano: un Buen Pastor Niño y una Divina Pastora. Juntas conforman un modelo devocional difundido en la pintura barroca sevillana.

Palabras clave: Buen Pastor Niño; Divina Pastora; Juan Ruiz Soriano; Bernardo Lorente Germán; pintura barroca sevillana.

This paper reveals a pair of paintings attributed to the artist Juan Ruiz Soriano: a Good Shepherd Child and a Divine Shepherdess. Together they conform a devotional model spread in Sevillian Baroque painting.

Keywords: Good Shepherd Child; Divine Shepherdess; Juan Ruiz Soriano; Bernardo Lorente Germán; Sevillian Baroque painting.
\end{abstract}

\author{
Tu bondad y tu misericordia me acompañan \\ todos los días de mi vida, \\ y habitaré en la casa del Señor \\ por años sin término $(\mathrm{Sal} 23,6)^{1}$
}

\footnotetext{
* Este trabajo se ha realizado gracias a un contrato de formación predoctoral (Personal Investigador en Formación P.I.F.) del V Plan Propio de la Universidad de Sevilla.

${ }^{1}$ Para Lina.
} 
La imagen de Jesucristo como Buen Pastor fue difundida en el arte cristiano a partir del siglo III a través de pinturas en las catacumbas, relieves en los sarcófagos y, ya en el siglo V, en mosaicos ${ }^{2}$. Esta iconografía hay que vincularla con la tradición evangélica que nos refieren Lucas y Juan en sus escritos neotestamentarios: Jesús es el Buen Pastor y da la vida por sus ovejas, que son las almas de los fieles. Normalmente se representaba a Cristo con una oveja sobre sus hombros, según nos narra el texto lucano: "Cuando encuentra la oveja perdida (Cristo), la carga sobre sus hombros" (Lc 15, 6). El cristianismo de los primeros siglos adoptó para representar esta escena un modelo pagano, el Hermes crióforo: un joven pastor que porta sobre sus hombros a una oveja. Este personaje estuvo asociado en la Antigüedad a la protección de los rebaños y era además el encargado de guiar a las almas en el mundo de los muertos ${ }^{3}$.

Esta imagen de Jesús como Buen Pastor, que en muchas ocasiones, aunque no siempre, adoptó esta iconografía de crióforo de la tradición clásica, decayó notablemente durante la Edad Media para reaparecer con fuerza durante el periodo barroco, auspiciado principalmente por las enseñanzas contrarreformistas. La oveja perdida es el alma descarriada que cuando se arrepiente de sus pecados, es redimida por Cristo, que la acoge hasta dar la vida por ella, de la misma forma que el pastor llega a luchar contra el lobo -el mal- hasta dar la vida por sus ovejas. Como señala el evangelio de Juan, Cristo conoce a sus ovejas y da la vida por ellas, hecho que se asocia a la muerte de Cristo como sacrificio vicario. La imagen del Buen Pastor hay que asociarla, por tanto, con la muerte vivificadora de Cristo en la cruz, con la que da vida al mundo.

La recuperación de la iconografía de Jesús como Buen Pastor durante la Edad Moderna fue especialmente popular en España, con un especial protagonismo en la pintura barroca sevillana gracias a Bartolomé Esteban Murillo (1617-1682). Este artista representó al Buen Pastor en edad infantil, acompañado de sus ovejas y en reposo, en mitad de un agradable ambiente campestre. La belleza formal y espiritual de esta imagen es característica de la exquisita sensibilidad que $\mathrm{Mu}-$ rillo supo otorgar a sus tipos infantiles, y contribuyeron a otorgar extraordinaria popularidad a este modelo iconográfico ${ }^{4}$. En muchas ocasiones la pintura del Buen Pastor formaba pareja con otra de San Juan Bautista Niño, aludiendo en su conjunto a Jesús como Agnus Dei, cordero de Dios que salva a la Humanidad de

2 RÉAU, Louis: Iconografía del arte cristiano. Vol. II. Barcelona, 1996, pp. 37-39.

${ }^{3}$ CHEVAlier, J. y GHEEBRANT, A.: Diccionario de los símbolos. Barcelona, 2015, p. 558.

4 Véase al respecto un artículo publicado recientemente por PÉREZ LÓPEZ, Nerea V.: "La iconografía del Buen Pastor Niño y su vinculación con la pintura barroca sevillana", Laboratorio de Arte, 29, 2017, pp. 311-328. 
sus pecados ${ }^{5}$. El culto y devoción a los Santos Primos puede constatarse en Sevilla desde comienzos del siglo XVII, fecha en la que podemos ubicar la realización del retablo del convento de Santa María del Socorro ejecutado por Juan Martínez Montañés con pinturas de Juan de Uceda ${ }^{6}$. En este se haya una obra de este pintor, fechada en 1610, que nos presenta a Jesús con San Juan Bautista, juntos en edad infantil.

En este ambiente pictórico debe contextualizarse la pareja de pinturas que presentamos, formada por un Buen Pastor Niño (Figura 1) y una Divina Pastora (Figura 2) ${ }^{7}$. Su autor debe considerarse como anónimo, aunque perteneciente al entorno de Juan Ruiz Soriano (1701-1763), pues por sus características formales se encuentra en la misma órbita de la producción de este pintor. Respecto a los modelos iconográficos, el autor es deudor de los tipos establecidos por Bernardo Lorente Germán (1680-1759) ${ }^{8}$.

La Virgen María como Divina Pastora muestra la iconografía tradicional de esta advocación fomentada por el capuchino fray Isidoro de Sevilla a partir de 1703. El pintor Alonso Miguel de Tovar supo dar materialidad a la inspiración que tuvo el fraile y popularizó el modelo iconográfico de María como Divina Pastora de las almas, que numerosos pintores sevillanos como Bernardo Lorente Germán ${ }^{9}$ y Juan Ruiz Soriano ${ }^{10}$, entre otros muchos anónimos, reprodujeron a lo largo del siglo XVIII.

Respecto al Buen Pastor Niño, es preciso señalar que aunque nuestro objetivo es dar a conocer sendas pinturas, hemos fijado nuestro interés en esta última, dado su atractivo iconográfico. Su particularidad reside en que Jesús Niño toma la iconografía de un Hermes crióforo, cuando lo habitual en aquellos años era adoptar el modelo murillesco del pequeño Jesús acompañado del rebaño, sin

${ }^{5}$ Sobre Murillo y el modelo iconográfico del Buen Pastor, véase VALDIVIESO, Enrique: Murillo. Catálogo razonado de pinturas. Madrid, 2010, pp. 166-168, nº 170, 242 y 356.

${ }^{6}$ En la actualidad pertenece a la colección del Museo de Bellas Artes de Sevilla, aunque se encuentra depositada en la iglesia de la Anunciación de esta ciudad.

${ }^{7}$ Se trata de una pareja de pinturas adquiridas a comienzos de este siglo en el mercado de arte y que actualmente se conservan en una colección particular de Son Servera (Mallorca). No se conocen sus medidas. Agradezco al profesor Enrique Valdivieso el conocimiento de estas pinturas y sus ánimos e inspiración para escribir sobre ellas.

${ }^{8}$ Sobre Lorente Germán y la producción de pintura devocional de parejas del Buen Pastor y la Divina Pastora, véase VALDIVIESO, Enrique: "Aportaciones al conocimiento de los discípulos y seguidores de Murillo", Goya, 169-170-171, 1982, p. 78.

9 VALDIVIESO, Enrique: Historia de la pintura sevillana. Sevilla, 1986, p. 311; y VALDIVIESO, Enrique: Pintura Barroca Sevillana. Sevilla, 2003, pp. 504-515.

${ }^{10}$ VALDIVIESO, Enrique: Historia..., op. cit., p. 317; y VALDIVIESO, Enrique: Pintura Barroca..., op. cit., pp. 516-524. 
portar ninguna oveja o cordero sobre sus hombros ${ }^{11}$. Lo fundamental en esta pintura es que la tradición iconográfica cambió para incorporar un tema clásico; no creemos que fuera algo novedoso pero se trata del primer modelo conocido de la pintura sevillana. Sin duda debió tener aceptación devocional, pues se ha conservado una obra casi idéntica a la que presentamos, en una colección particular de Granada (Figura 3) ${ }^{12}$. A pesar de ser un modelo excepcional en las artes plásticas sevillanas, esta iconografía inspirada en el crióforo de la Antigüedad clásica tuvo continuidad al menos hasta el siglo XIX, como lo demuestra un Buen Pastor del escultor Joaquín Bilbao ${ }^{13}$.

El fundamento teológico de la devoción al Buen Pastor ya hemos comentado que se encuentra fundamentalmente en el capítulo 10 del evangelio de Juan, especialmente en los versículos 11 al 16, donde Jesús se identifica como el Buen Pastor que da la vida por sus ovejas. También en Lucas 15, 6. No obstante, su origen puede rastrearse en el Antiguo Testamento donde se menciona que el pueblo de Dios es su rebaño y el Señor es su pastor (Sal 23) y los gobernantes indignos de Israel son los malos pastores (Jr 23, 1-6; Ez 34, 1-31). Los profetas Ezequiel y Jeremías denuncian la dispersión de las ovejas del rebaño y a los gobernantes que no han procurado su cuidado. Jesús condenó a aquellos que habían dispersado a las ovejas del rebaño: "Yo mismo buscaré mi rebaño y lo cuidaré". Para cumplir la promesa, anunció la llegada de un pastor que las apacentará: Cristo. Cuidará y velará por ellas. Cristo viene a reunir a las ovejas dispersas de su rebaño. Las conoce, las conduce y da la vida por ellas ${ }^{14}$.

La devoción al Buen Pastor durante finales del siglo XVII y comienzos del XVIII tiene su reflejo visual en el arte, pero con anterioridad ya se había desarrollado copiosamente gracias a la difusión de las prédicas y sermones, cuya

${ }^{11}$ No obstante, se conserva un dibujo de Bartolomé Esteban Murillo en el Paul Getty Museum de Malibú, en el cual se representa a Jesús Niño portando a una oveja sobre su hombro izquierdo, adoptando una postura más dinámica pero dispar a la que el tipo iconográfico del Buen Pastor acostumbra tener, con el animal reposando sobre sus hombros. Véase PÉREZ LÓPEZ, Nerea V.: "La iconografía...", op. cit., p. 326, fig. 6.

12 CASTAÑEDA BECERRA, Ana $\mathrm{M}^{\mathrm{a}}$ : Los Cieza: una familia de pintores del Barroco granadino: Juan, José y Vicente. Granada, 2000, p. 123, lám. 19; y PÉREZ PÉREZ, Marco Antonio: "Buen Pastor", en El barroco en la pintura. Córdoba, 2005, pp. 76-77. En estas publicaciones solo se indica que se trata de un óleo sobre lienzo, pero se obvian las medidas.

13 Dada a conocer en ÁLVAREZ CRUZ, Joaquín: "El Divino Pastor: una talla polícroma de Joaquín Bilbao", Laboratorio de Arte, 14, 2001, pp. 331-341.

${ }^{14}$ CHAPA, Juan: "Los discursos y diálogos de Jesús", en CHAPA, Juan (ed.): Introducción a los escritos de san Juan: Evangelio, Cartas y Apocalipsis. Pamplona, 2011, pp. 144-146. 
impresión fue muy abundante durante la Edad Moderna ${ }^{15}$. Puede constatarse además que esta devoción al Buen Pastor en compañía de la Divina Pastora, tuvo repercusión en el territorio hispanoamericano, como así lo ilustra una pareja de obras de Miguel Cabrera conservadas en el Museo Nacional del Virreinato de México, que muestra al Divino Pastor y a la Divina Pastora, con la peculiaridad de que Cristo aparece en edad adulta, reposando en mitad de un campo junto a las ovejas de su rebaño.

Fecha de recepción: 29 de septiembre de 2017

Fecha de aceptación: 12 de abril de 2018

${ }^{15}$ Ejemplo de ello: DE BARCIA ZAMBRANA, José: Despertador Christiano, Divino y Eucharistico de varios sermones de Dios... Madrid, 1695, obra popular entre sacerdotes para la inspiración y composición de pláticas piadosas. 


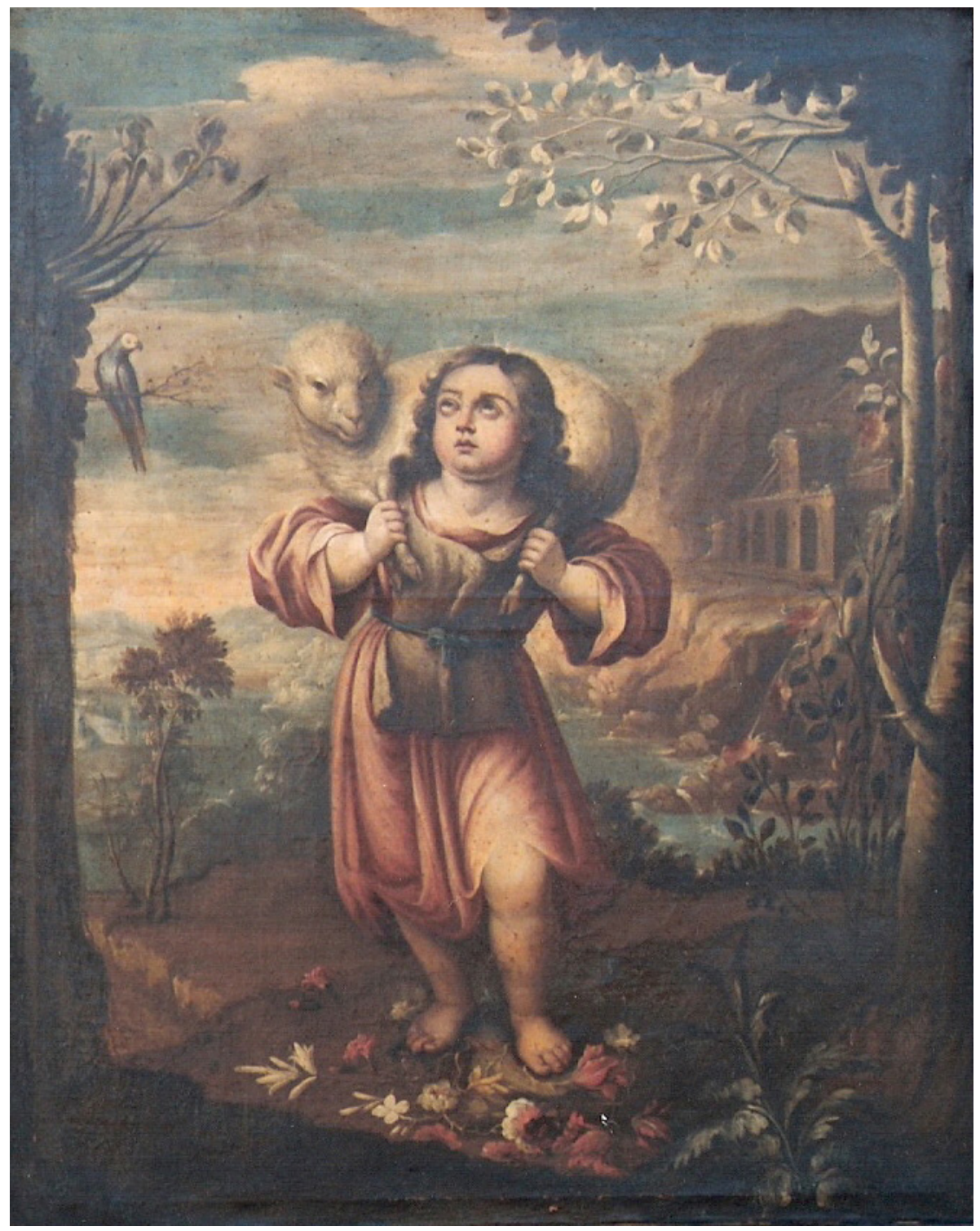

Figura 1. Círculo de Juan Ruiz Soriano, Buen Pastor, colección particular, Son Servera (Mallorca). 


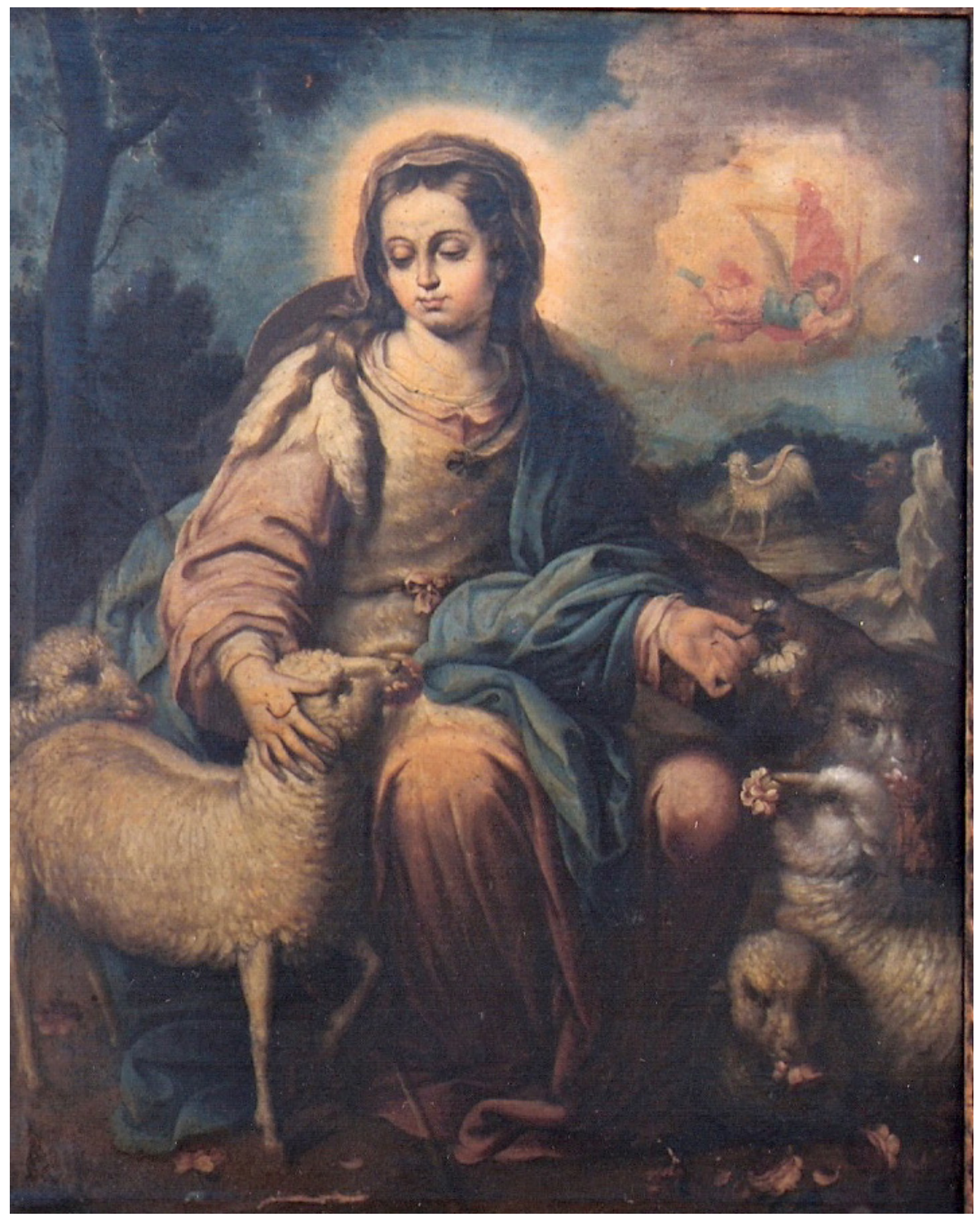

Figura 2. Círculo de Juan Ruiz Soriano, Divina Pastora, colección particular, Son Servera (Mallorca). 


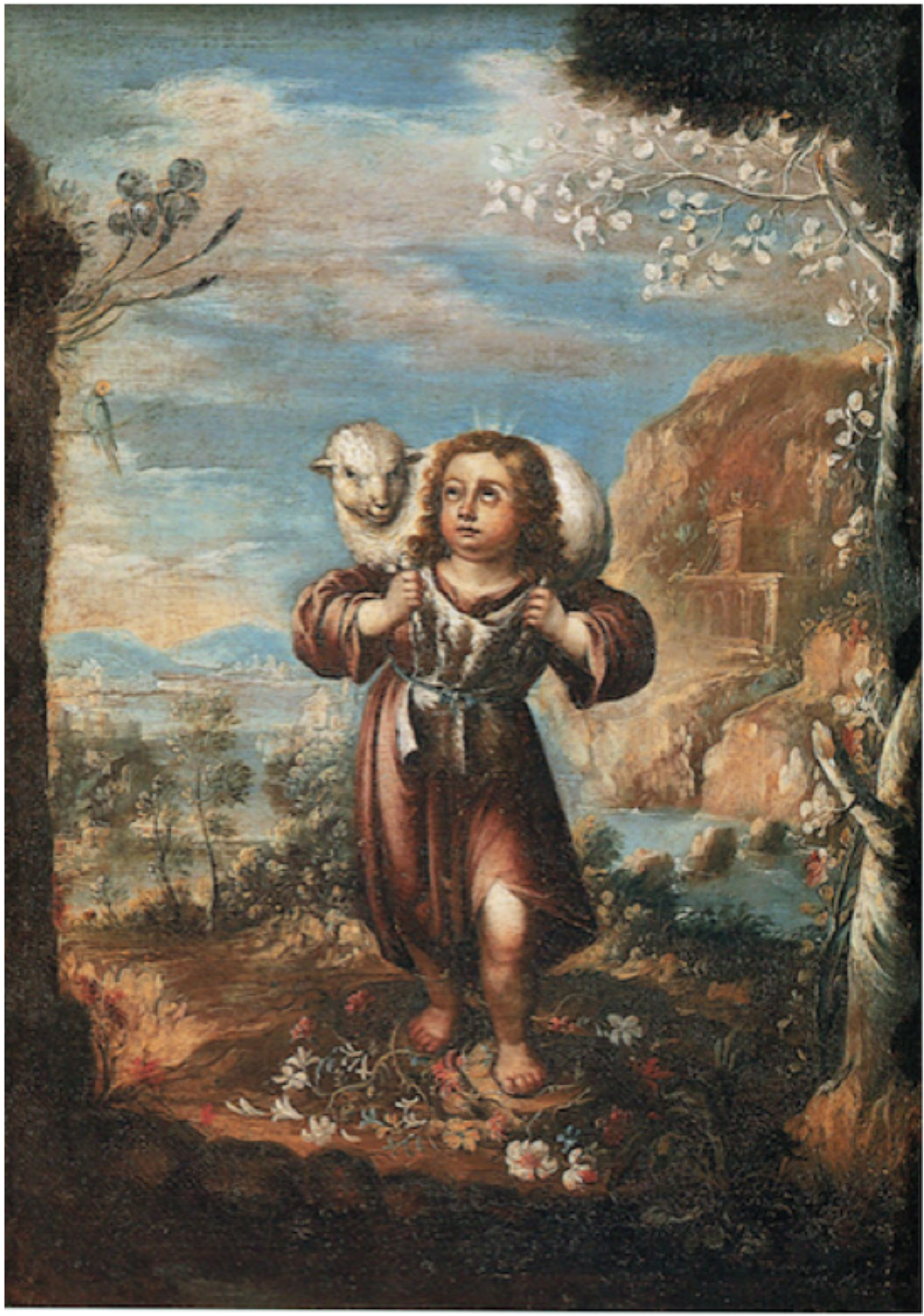

Figura 3. José de Cieza y Flores, Buen Pastor, colección particular, Granada. 